\title{
Integrated Teaching Methods based on Simulation Applied in Technical Colleges
}

\author{
Dayong Huo \\ Department of Physics, Kashgar Teachers College, Kashgar, 844006, China \\ hnnyhdy@163.com
}

Keywords: Simulation Teaching; Integrated Wiring; Teaching Reform; Vocational Education; Integration of Theory and Practice.

\begin{abstract}
To develop students' professional competence, vocational colleges use the teaching methods based on simulation widely. Under the simulated production environment, students can learn practical skills. After the experience of the work process, students are able to adapt to the future work quickly. This teaching method combines theory with practice, which is applied by the double-qualified teachers in the classroom. In teaching practice of two different higher vocational colleges, researchers have obtained satisfactory teaching effectiveness.
\end{abstract}

\section{Introduction}

In the colleges of engineering, the ideal teaching environment is real line engineering sites.[1] Chinese Ministry of Education and Vocational and Adult Education Department propose five requirements for the vocational colleges. Specific requirements include the following. Professional career positions are consistent with the industry jobs; professional courses are consistent with occupational standards; teaching process is consistent with process of production; diploma is consistent with vocational qualification certificate; vocational education is consistent with Lifelong Learning.[2] In order to promote professional competence, foreign advanced teaching institutions often use integrated teaching methods based on simulation. Vocational colleges in China utilize the centralized professional theoretical teaching first, and then set up the training segment operating skills for students. Currently, in the majority of Chinese vocational and technical schools, practice teaching is carried out in the training base outside the campus.[1]

Usually the training base outside the campus is an actual industrial production site. There are some problems in the traditional practical teaching, which has a negative impact on the quality of teaching. First, there is a contradiction between the production process of the project site and the teaching plan. Teaching schedules need to be made according to the actual production process. However, it is too difficult to coordinate the teaching plan and the actual production process because of some uncertainties on the work site. Secondly, training teaching requires all students to participate, which is difficult to be realized in the production line. Third, continuity of learning is very important for practice teaching. Nevertheless, the seasonal characteristics of the production process make it difficult to complete the entire learning process. Fourth, the reception capacity of the most Chinese enterprises is limited nowadays. For the large number of students in vocational colleges, it is sometimes difficult to meet teaching needs in the same production site. Fifth, decentralized training base makes it difficult for subsequent education for the graduates. In order to solve these problems, researchers used integrated teaching methods based on simulation in technical colleges. [1]The integrated teaching practice has achieved good teaching results in the vocational colleges in Henan Province.

\section{Integration of Theory and Practice Teaching Ideas}

Simulation teaching methods use simulator or simulation scenarios, so that the participants can play a role in the near reality. This method combines with the scene teaching, field teaching, case teaching and other teaching mode. [1]Simulation teaching can provide students with a realistic simulation 
environment. Students are trained in the organization of production, process procedures, on-site technology, etc. Students play a specialized role in a simulated working position, so they can quickly adapt to the future jobs. Simulation teaching methods accords with the reform ideas of the China's Ministry of Education about the vocational education. Modern teaching model is the reform goal of China's vocational education. Virtual processes, virtual technology, virtual production adopted in the new teaching methods can improve teaching efficiency and effectiveness.[2]

Researchers utilize the teaching task of "intelligent building security system debug" as an example to illustrate the simulation teaching methods. In the teaching case, the purpose of the integration of theory and practice of teaching is to impart the theoretical knowledge related to the security, intelligent building. At the same time, researchers have to teach the operating methods about the security project at the job site, so that the students can become assembly and commissioning professionals in the high-end intelligent building security systems. Such professionals have both a theory of knowledge and practical skills at the production site.

About the specific security engineering for intelligent building, the ability of students include the following: Selection about the security engineering materials, electrical and HVAC lines installation process requirements, collaboration with the construction and decoration works, organization of production, project management and cost management, field evaluation of production jobs, etc. As described before, if researchers carry out these teaching plans in the actual work site, the teaching time, procedures and the construction period will become insurmountable obstacles. Researchers use simulation teaching in teaching practice, so the synchronization of theory and practice can be realized. Researchers offer a real full construction environment about intelligent building in the teaching site, and the teaching tasks are performed by two qualified teachers from the production line. Teachers can train the theoretical and practical abilities of students according to security engineering process, and they also impart the knowledge about production management. After training under the complete production process, students' comprehensive vocational ability can be improved. In the teaching program, students play an important role in the teaching work. The basic unit consists of specific practice teaching modules. The teaching content of theory and practice is divided into five high-demand modules including technical support, working conditions, on-site process, site control, engineering evaluation. According to the required skill of construction workers, supervisory staff, estimators and administrators, and teachers guide students to master the relevant theoretical knowledge and skills. Students' ability to deal with problems can get promoted, and students are able to learn the correct technique. Researchers have designed a specific work environment at each end demands module. The student situation in passive learning is changed, and their active learning enthusiasm is mobilized.

\section{Implementation procedures for integration teaching of theory and practice}

Design. In accordance with the requirements of intelligent building class, researchers completed the teaching plan of security engineering. The integration plan of theory and practice contains theoretical issues and practical training topics, and each topic corresponds to an actual skill needs. Each topic has a perfect tutorial, drawings, text, technology, national standards, documents and other technical information. Meanwhile, the teaching environment requires adequate tools, equipment, materials for students. In each step of the work, the standard operating experience from actual production line serves as a reference. Students use the practical experience to fix, compare and improve their own ideas and working methods. Therefore, within the normal schedule on the theory and practice of teaching, it is ensured to achieve the teaching purpose.

Arrangements for Theory Teaching. In the beginning of teaching, preview and discussion related to the topics is arranged. Teachers analyze and explain the theoretical knowledge in a practical work environment, so that students can fully understand the relationship between all the theoretical knowledge and practical operation. At the same time, teachers should arrange relevant theoretical 
development training. In security engineering, researchers arrange reasonable teaching topics, including the contrast of the new and old national standard, development of PTZ equipment, application status of LED lighting, and the security investigation in intelligent building.

Teaching Grouping and Task Allocation. In the integration teaching of theory and practice, teachers will break down each task of teaching subject. In the form of organization of the production site, the students were divided into several groups. Teachers act as a job site foreman, and the students were divided into several operational teams which consist of seven people. Each working group will include captain, union leader, material man, service tools keeper, technicians, timekeeper, and project supervision staff. Each member is in charge of the corresponding work in accordance with the requirements of the production site. In the first class, teachers should explain the production tasks, work standards and method of operation, which is subordinate to a specific role, so that all students can understand the real production workflow and working methods. Each student's role in the work process can be transformed into another, which makes each member receive comprehensive training. In the process of teaching, teachers should explain the production management, site coordination, project supervision, GB implement and other content.

\section{Teaching Procedures and Methods}

After teaching the elementary theoretical knowledge, teachers should explain the relevant knowledge to students. In order to implement the integration teaching of theory and practice, students are divided into several groups and assigned to appropriate roles. Educating training includes the following five steps.

Security Engineering Design. Each working group will receive a security engineering design task book, and then begins to design the technical solutions. After submitting a complete security design, each group will have an academic discussion, and teachers will comment on each program. According to the reference scenario provided by teachers, each group should revise their plan, so that the next step in the work plan for each team is determined. Each member must complete their own program in accordance with the design requirements, which is an alternative for group submission. In this step, the student's role is technicians and administrators, and the teacher's role is technical leadership and technical consultants. In this process teachers should give design tasks, and educate management methods and operating techniques.

Preparation Process. Under the previous design, each team must prepare the construction process in security engineering. The specific tasks include the division of the construction process, materials management, schedule of working hours, and the budget of security engineering. After the brainstorming of techniques and budget, teachers should make timely comment. According to standard protocols, each team must revise individual program. Such follow-up work content is determined.

Student's role is technicians and administrators. Teacher's role is workshop director and technology leader. During this time, teachers should complete the preparation process, and prepare the work plan and budget book. Teachers should help students to understand a variety of materials, and demonstrate how to use the tools properly.

Preparation for Implementation. According to the division of work and process instructions, each team member must fill out requisition. After receiving the materials and tools, teachers guide students to do the preparatory exercises before construction in accordance with the process requirements. These exercises include the use of tools, wire connections, pipeline installation, etc. After brainstorming and teachers' comprehensive comment, construction plans will be compiled out. In the classroom teachers should unify the work content and production steps. In this step, the student's role is material administrator, administrator tools, construction supervisor, and the teacher's role is a consultant and superiors. At this stage, the teacher should have strong management skills and practical ability. 
Security Project Realization. In accordance with the drawings and process requirements, students can perform cabling practice in simulation training room. Teachers should guide students to practice correctly and demonstrate operations for each team. The construction workers and supervisory staff of each group will check the working conditions and assess the work result. Students' final assessment will be carried out by teachers to evaluate students' training. Students will discuss some of the key technologies during the operation, and that teachers should show how to conduct standardized operations. In the teaching process teachers should pay attention to the synchronization of the teaching content. During this period the student's primary role is technicians, supervisory staff and operation workers, teachers' role is a technical consultant and on-site mentors.

Inspection and Evaluation. After the construction work is completed, each team will check the overall project and make the project accounts. Teachers should explain the entire operations of security system engineering, and evaluate the construction work of each group. Finally the teacher will conduct theoretical and practical assessment to evaluate students' achievement. Here the role of student is accounts employee, quality inspector and representatives of the parties involved in the project. The teacher's role is a technology leader and management leader.

\section{Required Conditions and Teaching Effectiveness}

In the implementation process, the entire teaching should fully comply with the actual production of security engineering. When students are divided into specialized groups, they have to carry out technical exchanges, drawings and other technical management practice. When the students were divided into production teams, they executed meetings before and after the daily production. It is very important to carry out the activities of safe and civilized production in the student's training. At every meeting of the engineering teams, every student needs to talk about the work situation. In the training process, students must master all the requirements of each job. In the teaching process, teachers give students theoretical and practical knowledge. Meanwhile, teachers should focus on the training of students' language skills and teamwork spirit. After the completion of the task of teaching, teachers should make the evaluation of each student's career potential and employment tendencies.

Here the teaching establishments of theory and practice should be integrated classrooms. These classrooms can accommodate about forty students, and offer five construction environments to simulate security projects. At the same time, these classrooms are able to meet forty students to do design work. The textbook should be tutorials on integration of theory and practice, which contains enough drawings and information from the real production line. Teachers should be engineer or technical personnel from the production line, and they should have strong operational capability and rich management experience.

We have made the integration teaching of theory and practice, which take simulation teaching as a carrier. Students mastered the skills of field operations, and meanwhile they had a deep understanding of technology, management and production processes. The integration teaching achieved the communication between learning and production processes successfully. The authors have carried out the reform of integration teaching in three courses in two vocational colleges. The trained students have shown strong adaptability in practice, and they received a good evaluation from the relevant enterprises.

\section{Conclusion}

Simulation teaching pedagogy is used as a carrier of integration teaching of theory and practice. This method conforms to the requirements of higher vocational education reform proposed by the Ministry of Education, and these innovations will lead the development of vocational education. The teaching method can effectively improve the reception capacity of training units, as well as the theory and practice of teaching quality has been guaranteed. Traditional teaching methods are implemented in accordance with the personnel training programs, and the latest teaching methods will remain the 
traditional advantages. At the same time, the teaching philosophy also solves two constraints learning requirements, which are not available in the actual production site. The first question is about the training details, and the different teaching methods can ensure students' systematic training on a certain technical aspects. For example, the training sessions in our case include financial calculations, design, supervision, technology, field operations, skills testing, career planning guidance, and so on. The second question is about the training schedule, and new teaching methods can ensure students' synchronous training. As in this case, forty people can learn the theory and practical knowledge synchronously, and the new method can guarantee students to be well organized.

\section{References}

[1] H. D.Y,W.X.J, and J. D. The Utilization of Simulation Teaching Method in Practice Teaching in Higher Vocational College, http://www.cmvet.com.

[2] Some suggestions on promoting the reform and innovation of higher vocational education and leading the scientific development of it, given by the Ministry of Education, (2011)12th, the Education of Vocation and Adult [D]. 2011.08.

[3] L.F, Y.K.Q: Employment-oriented-Higher Vocational of Graduation Design Inevitable Choice,

Chinese Vocational and Technical Education, 13 (2007) 44-45.

[4] L.M.H: Entrepreneurship education and the Participatory teaching, Chinese Vocational and Technical Education, 20 (2010) 66-68.

[5] L.H.X: Research on the Faculty in Higher Vocational Institutions, Chinese Vocational and Technical Education, 36 (2010) 84-87.

[6] QUAN Shao-hui, Study on the Quality Monitoring and Evaluation System Establishment of Vocational College Integrated Teaching. Northwest A\&F University, XIAN, 2014, 21-30.

[7] WANG Ying-yan, LI Chun-yan, Application of Simulation in Practice Teaching of Diagnostics. Journal of Dalian Medical University, 36(2014)605-608

[8] CHEN Shi-ping, JIANG Xi-ming, LI Ci, Practice Teaching Reform of Engineering Majors in Local Colleges and Universities. Research and Exploration in Laboratory, 5(2013)186-190.

[9] HU Xian-min,A Study on Theoretic and Practical Integration Teaching Model in Colleges. Journal of Zhejiang International Maritime college,2(2010)55-57

[10] CHEN Bing-he, On Theoretical Basis and Approach to the Teaching Reform of Projected Courses in Higher Vocational College. Exploration and Research of Vocational Education, 13(2010)19-21. 